\title{
Finite Element Modeling and Analysis of Precast Reinforced Concrete U-Shaped Box Culvert Using ABAQUS
}

\author{
Zenagebriel Gebremedhn*, Guofu Qiao, Jilong Li \\ School of Civil Engineering, Harbin Institute of Technology, Harbin, China \\ Email address: \\ zencheboyy@gmail.com (Z. Gebremedhn), qgfhit@163.com (Guofu Qiao), leekeelung@126.com (Jilong Li) \\ ${ }^{*}$ Corresponding author
}

\section{To cite this article:}

Zenagebriel Gebremedhn, Guofu Qiao, Jilong Li. Finite Element Modeling and Analysis of Precast Reinforced Concrete U-Shaped Box Culvert Using ABAQUS. American Journal of Civil Engineering. Vol. 6, No. 5, 2018, pp. 162-166. doi: 10.11648/j.ajce.20180605.14

Received: October 10, 2018; Accepted: November 12, 2018; Published: December 11, 2018

\begin{abstract}
This paper presents the finite element results of a parametric investigation of the U-shaped box culvert of prefabricated reinforced concrete subject to loading conditions. It was included outer size span length $4.80 \mathrm{~m}$, rise of $4.80 \mathrm{~m}$, laying width $1.5 \mathrm{~m}$ and $0.4 \mathrm{~m}$ slab and wall thickness. Its components consisted of two symmetrical u-shaped structures joined together using the tip at the end of the bell. It was not recommended for areas with excessive settlement where deep foundations were required. The upper and side ground pressure was considered in the culvert, which depends on the depth of the canal. The finite element method has been chosen for purpose of modeling and analyzing the structural behaver of the standard three dimensional solid and wire elements of the u-shaped box culvert under different loading conditions using ABAQUS-V6.14-4 due to its flexibility in creating geometry and material modeling. The culvert has been modeled using 3-D solid (C3D8R) elements reduce integration for concrete and 3-D wire (T3D2H) elements for reinforcement having geometric and material linearity as well as hybrid formulation. The reinforcement was modeled as rebar elements embedded in the surface element. Finally, the Finite element analysis (FEA) results were showed deflection and stress as well as effect of with and without distribution steel on the culvert.
\end{abstract}

Keywords: ABAQUS, Box Culvert, FEA, FEM, Precast Concrete, Reinforced Concrete

\section{Introduction}

Precast reinforced concrete culvert is a mini version of bridge since they perform similar tasks which is the strong, safe, stiff, and economical alternative for replacing deteriorating short section and elevation of the bridge. The culverts, however, generally differ from bridges because the upper part of the sewers not part of the road traveled. The underground canals are located in three general locations: at the lower part of the depressions where there is no natural water course, where natural currents cross the road and in the places necessary to pass the surface drainage that is transported inside the underlying ditches of streets and entrances to the adjacent property. Although there is a variety of styles and designs of underground canals in service, all the sewers can be classified into two basic types: rigid (concrete) and flexible (steel). These classifications are based on the main difference in how the structural loads are transported by the culvert and by the interrelation between the structure of the culvert and the surrounding soil. Rigid culverts are designed to resist bending moment; flexible are not. Culverts are also often described by their shape, which may be circular, arched, elliptical, or box. The box shape may be made more torsional rigid by adding internal web walls between the top and bottom surfaces. Culverts may also be made with multiple barrels for additional flow capacity. Most modern culverts are made from either corrugated metal, plastic, or reinforced concrete. Concrete culverts may be of either precast or cast-in-place construction, which may be posttensioned in the field. The advantage of the precast concrete box culvert mainly focusses on the construction of the main structure. [1-4] The construction link of the main structure of the cast in place box culvert are all completed in the field, occupying a large amount of field time. The main structure of the precast concrete box culvert is made in the prefabricated component factory. It can be carried out synchronously with the site cast in place construction and it does not occupy the site the construction period while the 
prefabricated component hoisting, assembling and connected parts anti corrosion processing are more efficient in the construction period. These structures include precast reinforced concrete box culvert. The most commonly used type is precast reinforced concrete box culvert due to reduces construction time and maintenance cost, particularly, they are ideal when the concrete batching plant is not near the construction site. Pre-cast box culverts are not recommended for areas with excessive settlement where deep foundations are required since deep foundations would have to be placed on shorter intervals with the use of precast sections making the installation excessively expensive. [5, 6] Currently, the maximum inner span length of a standard precast box culvert is $3.5 \mathrm{~m}$ based on Chinese code of standard. This span length is sometimes small to handle heavy water flow which may require the use of multiple sections placed side by side. In this case, the walls of adjacent culverts will act as a pier which may obstruct the flow and be associated with flooding problems. Therefore, developing new box sections with $4.0 \mathrm{~m}$ inner span length could prove to an economically alternative to multiple sections. Furthermore, this paper will present the finite element analysis (FEA) results of precast reinforced concrete u-shaped box culvert subject to loading conditions. [7-9]

\section{Materials and Methods}

The precast reinforced concrete u-shaped box culvert with $4.0 \mathrm{~m}$ inner span length were investigated. The u-shaped box culvert had a $4.0 \mathrm{~m}$ inner size rise, $0.4 \mathrm{~m}$ slab and wall thickness, $0.3 \mathrm{~m} \times 0.3 \mathrm{~m}$ haunch at each corner, and $1.5 \mathrm{~m}$ laying width, components are made from two symmetrical ushaped structures with outer size $2.52 / 2.28 \mathrm{~m} \times 4.8 \mathrm{~m} \times 1.5 \mathrm{~m}$, as well as strong concrete C40 and steel strength level $400 \mathrm{HRB}$ under consideration of 12 test loading conditions with deflection collected from 12 node location. Those are 4 nodes outside face and 8nodes inside face selected at appropriate location. The U-shaped box is usually combined with the two vertically symmetrical structures using the tip at the end of the bell.

The geometry of the u-shaped box culvert was a composite made up of concrete and steel which is modeled using 3-D solid (C3D8R/An 8 node linear brick 3 degree of freedom) elements reduce integration for concrete and 3-D wire (T3D2H/two node brick 3-D truss hybrid) elements for reinforcement having geometric and material linearity as well as hybrid formulation, and the various items concerned with modeling is addresses as follows; element type, material properties, assigning sections, defining step, interaction between elements, specify boundary condition, specify load location, mesh, creating job analysis and evaluating the viewed results using visualization.

The finite element modeling program, ABAQUS CAE 6.14 , was used for modeling the structural behavior of the $\mathrm{u}$ shaped box culvert, which can then be extruded in $\mathrm{x}, \mathrm{y}$ and $\mathrm{z}$ directions; its developed 3D solid model for the concrete (See Figure 1) and 3D wire for reinforcement by considering basic material parameters of the modeling as per [10] shown in Table 1. The rebar diameter of $14 \mathrm{~mm}$ and $16 \mathrm{~mm}$ was modeled as $\mathrm{T} 3 \mathrm{D} 2 \mathrm{H}$ using assembling of part instances the culvert surface element embedded to the rebar element. (See Figure 2)

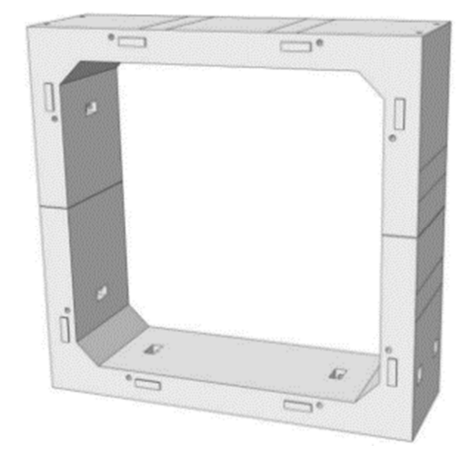

Figure 1. U-shaped box culvert concrete.

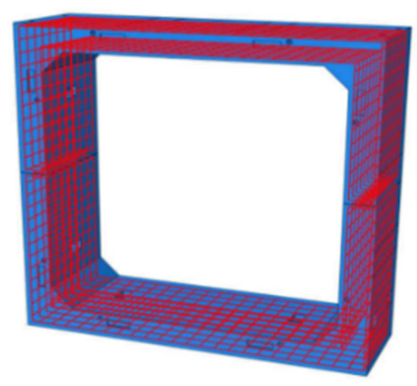

Figure 2. U-shaped box culvert concrete embedded reinforcement.

Table 1. Basic material parameters of the modeling.

\begin{tabular}{|c|c|c|c|c|c|}
\hline Item No. & $\begin{array}{l}\text { Modulus of } \\
\text { elasticity (MPa) }\end{array}$ & Poisson's Ratio & Density $\left(\mathrm{Kg} / \mathrm{m}^{3}\right)$ & $\begin{array}{l}\text { Tensile strength } \\
\text { standard value (MPa) }\end{array}$ & $\begin{array}{l}\text { Comprehensive strength } \\
\text { standard value (MPa) }\end{array}$ \\
\hline Concrete & $3.25 \mathrm{E} 4$ & 0.2 & 2400 & 2.39 & 26.8 \\
\hline Reinforcement & 2E5 & 0.2 & 7850 & 400 & 400 \\
\hline
\end{tabular}

After assembling and assigning the properties, an input file is created which is then imported to create mesh. A mesh contained nodes and elements but no geometry. This is useful for creating surface on concrete to apply load an area of $35 \mathrm{~cm} \times 150 \mathrm{~cm}$ at on roof and side wall and also for applying boundary condition on nodes at the bottom of the culvert with 1.5 second load analysis step. (See Figure 5) The ushaped box culvert had nodes at a distance of $200 \mathrm{~mm}$ from the edge of the culvert is retained to move along $\mathrm{Y}$ direction at one side and on the other side it is restrained to move in $\mathrm{X}$ and $\mathrm{Y}$ direction as shown in Figure 3 and Figure 4. Meshing is the process of generating nodes and elements. A mesh is generated by defining nodes and connecting them to define the elements. [11] 


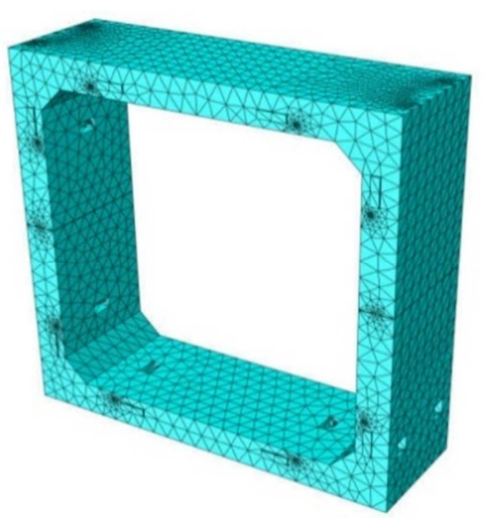

Figure 3. Mesh of u-shaped box culvert concrete.

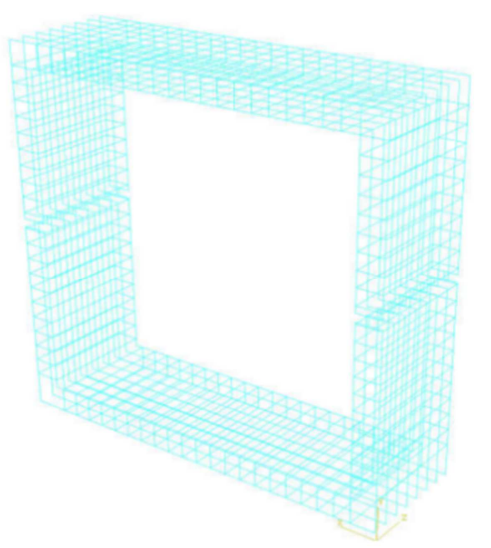

Figure 4. Mesh of u-shaped box culvert reinforcement.

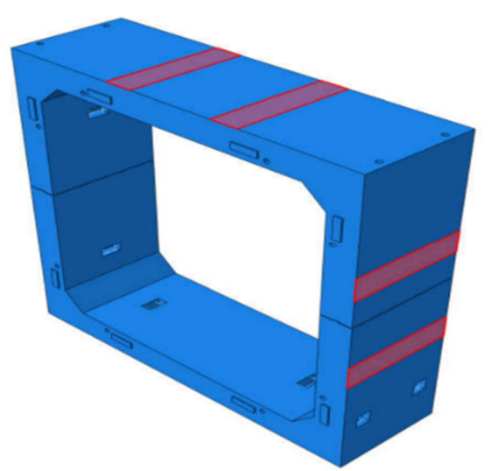

Figure 5. Load location of u-shaped box culvert.

\section{Result and Discussion}

The finite element analysis is a theory of numerical analysis commonly used for different engineering situations, since this method is susceptible to systematic programming for application of analysis problems. It is Computer Aid Engineering and is widely used in the analysis and design of many complex real-life systems. [12, 13] Therefore, the finite element method has been chosen for purpose of analyzing the structural behaver using ABAQUS- 6.14-4. To solve any kind of finite element problem, it is necessary to establish the analysis of the relevant work. After this phase, the extracted answers are displayed analytically and graphically.
Furthermore, when the solution is completed, the result can be viewed. These results may be of color contour plots, animations, XY-plots and tabular out of the result. It is analysis phase where the result $\mathrm{s}$ of analysis reviewed through graphics and graphs. The deflection is supported by visualization mode but crack is not supported by visualization mode and identify the level of stress at that point so that deflection is read in data files, which identifies the deflection elements using visualization mode. Alternatively, it is easy to identify the solid deformed and wireframe-deformed finite element modeling as presented in Figure 6. [11, 14, 15]

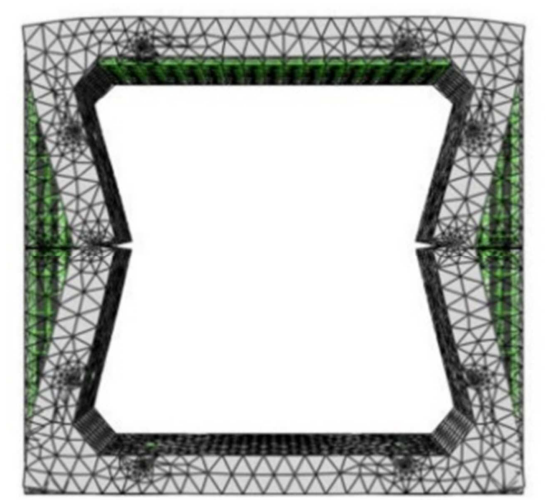

Figure 6. Deflection shape of the u-shaped box culvert.

Up on the application of the load, through the load across beam plate, on the outside face of the top slab and side wall panel at the certain distance, the u-shaped box culvert undergoes deflection. The side wall panel and floor slab deflects inward but the top slab deflected up ward of the ushaped box culvert.

The stress diagram of the structure under the normal use limit state control, the load capacity limit state control load and the maximum control load are observed respectively. In order to get the stress on the surface of the plate along the direction of its span, the observation side plate. The stress region is located in roof, floor slab and side wall panel of the u-shaped box culvert. (See Figure 7) [16]

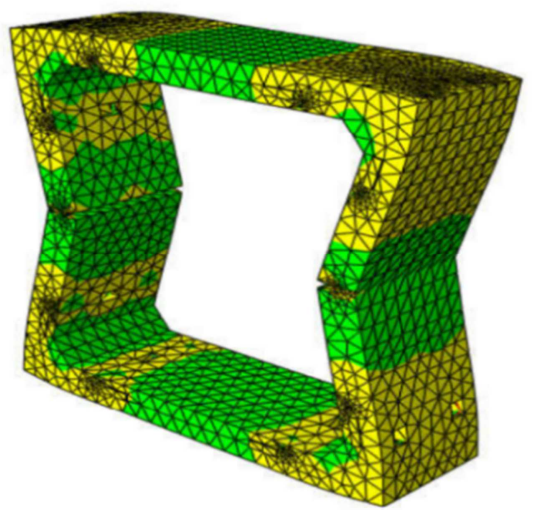

Figure 7. Contour for stress (Stress Region: yellow Color). 
Table 2. Summery of FEA data sheet.

\begin{tabular}{lllll}
\hline \multirow{2}{*}{ Events } & \multicolumn{2}{l}{ Load Test Controlling points $(\mathbf{K N})$} & $\mathbf{1 2}$ & $\mathbf{1 7}$ \\
\cline { 2 - 5 } & $\mathbf{7}$ & $\mathbf{9}$ & $100 \%$ & $148 \%$ \\
\hline Load (\%) & $59 \%$ & $74 \%$ & 484.60 & 719.20 \\
Vertical load (KN) & 285.00 & 359.60 & 178.00 & 264.20 \\
Right side upper load (KN) & 104.70 & 132.10 & 178.00 & 264.20 \\
Left side upper load (KN) & 104.70 & 132.10 & 312.50 & 463.80 \\
Right side lower load (KN) & 183.80 & 231.90 & 312.50 & 463.80 \\
Left side lower load (KN) & 183.80 & 231.90 & 293.12 & 435.04 \\
Average Load (KN) & 172.40 & 217.52 & 0.56 & 0.83 \\
Average stress (MPa) & 0.33 & 0.41 & 0.66 & 0.98 \\
Average Deflection (mm) & 0.41 & 0.49 & & \\
\hline
\end{tabular}

In the present study, the stress at various points of load for the u-shaped box culvert are shown in Figure 8 and Table 2. From the FEA investigation, average stress is not directly measurable but calculated using applied average load divided by its cross sectional area. Therefore, it was observed that the average stress is appeared firstly at $29.34 \mathrm{KN}(10 \%)$ trial test no. 2 with $0.06 \mathrm{MPa}$ and the maximum average FEA stress detected $0.83 \mathrm{MPa}$ at average loads of $435.04 \mathrm{KN}(148 \%)$ trial test no. 17. This implies that it needs greatest warning zone before failure at the stress region of the roof, floor slab and side wall panel of the u-shaped box culvert. (See Figure 7)

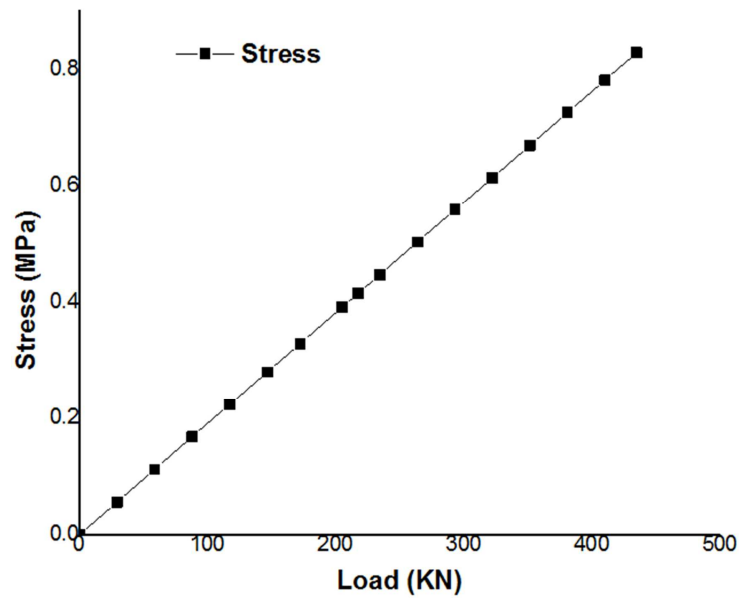

Figure 8. Load stress plot.

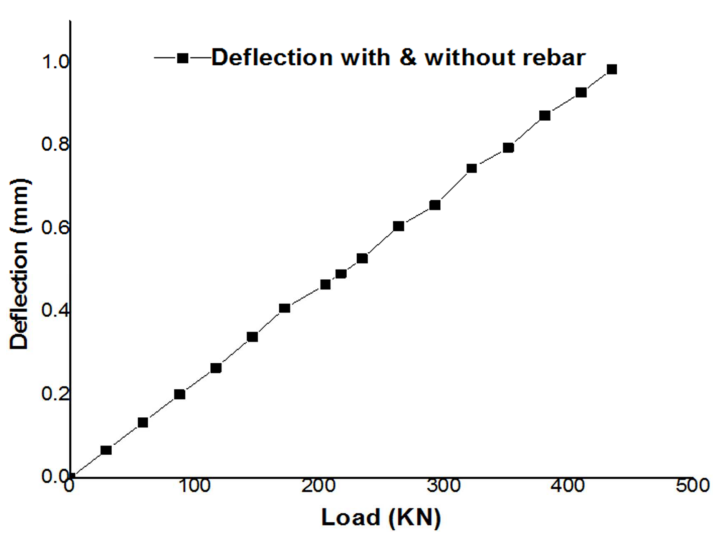

Figure 9. Load deflection plot.

Finally, Figure 9 presents the FEA results, for $u$-shaped box culvert with and without compression steel distribution showed that insignificant and its correlation also quite good.
The FEA deflection was appeared firstly at 29.34KN (10\%) trial test no. 2 with $0.07 \mathrm{~mm}$ and the maximum average FEA deflection detected $0.98 \mathrm{~mm}$ at average load of $435.04 \mathrm{KN}$ $(148 \%)$ trial test no. 17 . This implies the side wall panel and floor slab deflects inward but the top slab deflected up ward of the u-shaped box culvert. (See Figure 7)

\section{Conclusions}

In this report the modeling and analysis of a prefabricated reinforced culvert with finite element method was presented. The main test variables included deflection and stress, as well as the effect of with and without distribution of the steel in the canal. Based on interpretations and discussions of the FEA results, for $\mathrm{u}$-shaped box culvert with and without compression steel distribution showed that insignificant as well as the side wall panel and floor slab deflects inward but the top slab deflected upward. So that it needs greatest warning zone before failure at the stress region of the roof, floor slab and side wall panel with loads ranging from $234.50 \mathrm{kN}$ to $435.04 \mathrm{kN}(80 \%-148 \%)$ of the u-shaped box culvert.

\section{Acknowledgements}

This research was financially supported by the National Key Basic Research Program of China (973 Program CSC No. 2016GXZ133) and Zhongda Road and Bridge Group.

\section{References}

[1] M. Ahmed Alia Osman and E. Alarabi, "Development Formulation for Structural Design of Concrete Box Culverts," Practice Periodical on Structural Design and Construction, vol. 16, pp. 48-55, 2011/05/01 2011.

[2] A. Abolmaali and K. Garg Anil, "Effect of Wheel Live Load on Shear Behavior of Precast Reinforced Concrete Box Culverts," Journal of Bridge Engineering, vol. 13, pp. 93-99, 2008/01/01 2008.

[3] F. S. o. Y. W. D. Yijie, "Development and Application Prospect of Precast Prestressed Concrete Box Culvert," China Concrete and Cement Products, 2016.

[4] P. Jianzhong, "Analysis on the structural design of the sluice cover box" Shandong Industrial Technology, 2018. 
[5] K. Garg Anil, A. Abolmaali, and R. Fernandez, "Experimental Investigation of Shear Capacity of Precast Reinforced Concrete Box Culverts," Journal of Bridge Engineering, vol. 12, pp. 511-517, 2007/07/01 2007.

[6] A. W. W. h. G. S. Y. H. Y. B. H. Shiguang, "Brief Analysis of Design and Production of Prefabricated Box Culverts in Integrated Pipe Gallery," Concrete world/China Concrete, 2018 .

[7] L. Mengna, "Finite element structure analysis of underground box culvert," Zhengzhou University, 2014.

[8] W. Wei, "Research on Design Technology of Composite Culvert Frame Combination Culvert Structure," Xinjiang University, 2013.

[9] J. T.-C. o. Chinese, "precast concrete box culvert," China Concrete and Cement Products, 2018.

[10] C. o. China, Code for design concrete structures vol. GB50010: Publishing House of building Industry in China, Beijing (in Chineses), 2010.

[11] M. V. R. R. T. Tejaswini, "Analysis of RCC Beams using
ABAQUS," International Journal of Innovations in Engineering and Technology (IJIET), vol. 5, pp. 248-255, 2015.

[12] S. K. K. A. C. LANDE, S. A. MAHADIK., "Finite Element Analysis of Box Culvert," International Journal of Advanced Structures and Geotechnical Engineering, vol. 04, pp. 57-62, 2015.

[13] G. B. Xu Chuan, "Finite element analysis and internal force diagram of box culvert," Journal of Disaster Prevention and Mitigation, vol. 34, pp. 92-96, 2018.

[14] R. I. Pawtucket, Abaqus/CAE -V6.14-4-Users Guide, 2014.

[15] Y. Y. Liu Liyu, Liu Xian, "Finite element analysis of double replacement method for box culvert jacking," Journal of Building Construction, vol. 32, pp. 110-112, 2010, 32 (02): 110-112.

[16] A. J. Wang Shuhong, Jie Rula, Wang Pengyu, Liu Weihua, "Simulation of Force Performance of Precast Rectangular Box Culvert and Its Potential Failure Mode," Journal of Northeastern University (Natural Science), 2018. 